\title{
MEASUREMENT OF AGGLOMERATES SHAPE PARAMETERS WITH THREE- DIMENSIONAL RECONSTRUCTION BASED ON A LASER DISPLACEMENT SENSOR
}

\author{
J. P. Zavala De Paz ${ }^{1)}$, E. Castillo Castañeda ${ }^{1)}$, J. Soto Herrera ${ }^{2)}$, C. Turchiuli ${ }^{3)}$ \\ 1) Instituto Politecnico Nacional, CICATA Unidad Queretaro, Cerro Blanco 141, Colinas del Cimatario, 76090-Queretaro, Mexico \\ \jzavalad0900@ipn.mx,ecast63@yahoo.com) \\ 2) Universidad Autonoma de Queretaro, Cerro de las Campanas, 76010-Queretaro, Mexico (jush81@gmail.com) \\ 3) Agroparistech UMR GenIA1 1145, 1 avenue des Olympiades, 91744-Massy, France (christelle.turchiuli@agroparisttech.fr)
}

\begin{abstract}
The agglomeration of particles is a process that modifies the physical properties of a product originally manufactured as a powder. During milk powder agglomeration of fluidized bed, resulting agglomerates are sufficiently porous to improve the solubility of the final product but, at the same time, their rigidity decreases and agglomerates can be destroyed during packing. The porosity and rigidity properties depend on both the volume and shape characteristics of the agglomerates. This paper presents a three-dimensional reconstruction technique based on a laser displacement sensor (LDS) applied to characterize milk agglomerates. This technique allows three-dimensional scanning to estimate particle volume and extract shape parameters such as: sphericity, elongation and flatness ratio, shape factor and aspect ratio. This technique was implemented using a mechatronic device with two degrees of freedom. The device is composed of an angular positioning system to rotate the agglomerate and a linear positioning system to displace the LDS. Experimental result allows agglomerates classification according to shape parameters.
\end{abstract}

Keywords: agglomerated particles, laser displacement sensor, shape parameters, three-dimensional reconstruction.

(C) 2013 Polish Academy of Sciences. All rights reserved

\section{Introduction}

In the food industry the agglomeration process of powders increases the particle size as well as its porosity and then modifies end-user properties such as wettability, sinkability, dispersibility and solubility. The main application of agglomeration is to produce instant products (e. g. instant coffee, milk powder, cocoa beverages, etc.) that acquire the ability for dispersing and rapidly dissolving in liquids (water, milk, etc.) [1].

Furthermore, many of the physical and structural properties of agglomerates such as density, surface properties, size and shape, influence the particles rigidity and then modify their behavior during handling [2,3]. The measurement of these physical properties is important since they affect the behavior of powder particles during storage, packing and processing.

The size parameter (usually associated to diameter, surface or volume) describes the geometry of the object regardless of its form [4]. The shape parameter characterizes the object regardless of the size. Currently, the measurement of the shape parameters of agglomerates is performed from 2D data, usually from microscope images. One of the shape parameters frequently used in the characterization of objects is the sphericity. However, there are no works to report measurements of sphericity in the characterization of agglomerates of milk powder from $3 \mathrm{D}$ data. 
There are different methods for characterization of agglomerated particles. In [5] the shape of agglomerates is computed from 2D microscope images by finding the circle that best fits the estimated area on each image, assuming that particles have a circular shape. A highly accurate technique is the use of confocal microscopy [6] that creates sharp images of a specimen, normally blurred with conventional microscopes; however, stimulating fluorescence from dyes that should be applied to the specimen, can modifies the agglomerates properties. Another method to characterize agglomerate is the use of mercury porosimetry applying various pressure levels to the sample. This technique is not suitable to characterize agglomerates, normally fragile, that are broken during the measurement [7].

The work presented in [8] computes the porosity of fragile agglomerates from only three images acquired with a CCD camera. The work described in $[9,10]$ present a method based on silhouettes extraction of multiple views to estimate the volume of the envelope of milk powder agglomerates; agglomerates concavities are not considered. The works in [11-13] developed methods to estimate the shape of particles using 2D shape parameters from image analysis techniques.

The aim of this paper is to propose a methodology to characterize the shape of agglomerated particles of milk powder using 3D parameters. This methodology is based on a laser displacement sensor that allows a three-dimensional reconstruction of the agglomerated particles. This approach can be extended to measure other particle systems. The shape of the agglomerates was analyzed using the following form factors: elongation, flatness, aspect ratio and sphericity. Also, the particle volume is determined since it is used as a basic parameter to determine the particle sphericity.

\section{3D reconstruction system}

\subsection{Positioning system}

The positioning system is shown in Fig. 1. The agglomerate is placed on the object holder that rotates, driven by a stepper motor, at $\Delta \theta$ degrees increments controlled by a PIC-STEP control board. The laser displacement sensor (LDS) is rigidly mounted on a linear positioning system that moves along $z$-axis at $\Delta z$ increments $(\Delta z=30 \mu m)$.

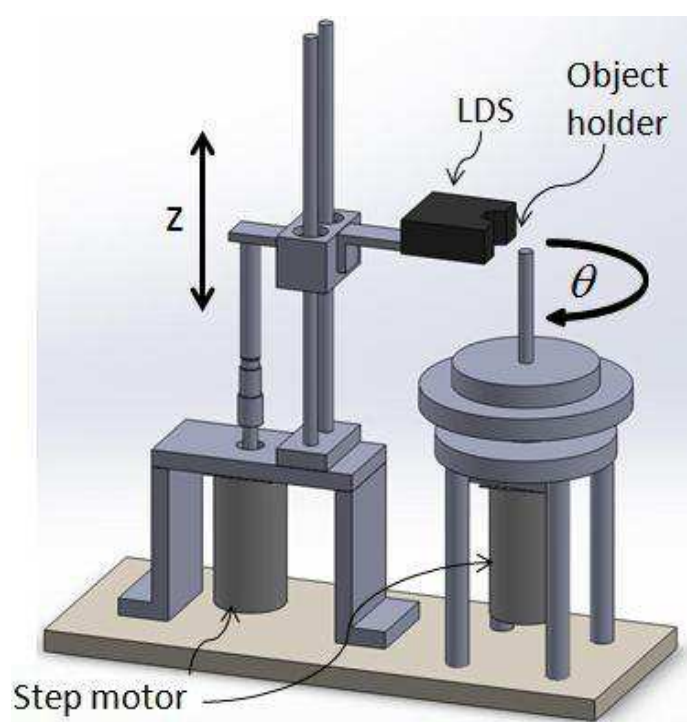

Fig. 1. 3D reconstruction system. 


\subsection{LDS description}

The LDS used works on optical triangulation principle. A laser diode (wavelenght $650 \mathrm{~nm}$ ) is the light source, projecting a spot onto the surface to be measured. The LDS is mounted on the linear positioning system. The LDS controller estimates the distance between its emitter and the target (agglomerate surface). Fig. 2 shows the laser triangulation principle.

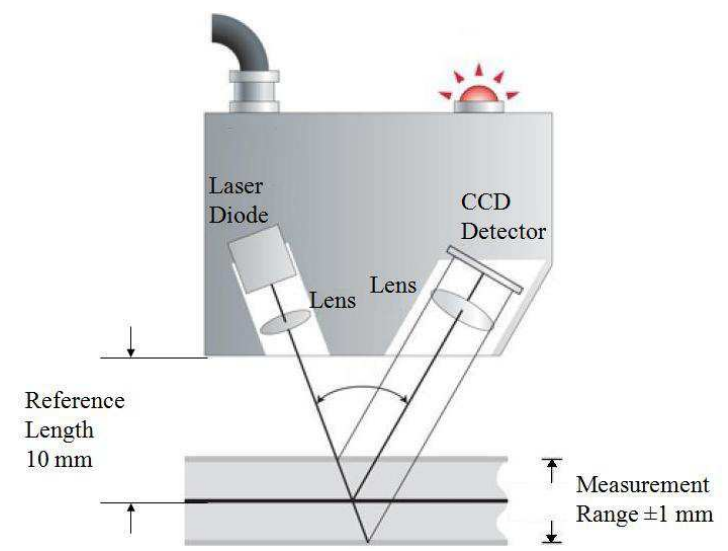

Fig. 2. Laser triangulation principle.

The measurement technique is based on the LDS model LK-G10 from KEYENCE [14]. Table 1 shows the technical specifications of the sensor.

Table 1. Technical specifications of LK-G10 sensor from KEYENCE.

\begin{tabular}{|l|l|}
\hline Reference length & $10 \mathrm{~mm}$ \\
\hline Measurement range & $\pm 1 \mathrm{~mm}$ \\
\hline Wavelength & $650 \mathrm{~nm}$ \\
\hline Spot diameter & $20 \mu \mathrm{m}$ \\
\hline Repeatability & $0.01 \mu \mathrm{m}$ \\
\hline Response (frequency) & $50 \mathrm{kHz}$ max. \\
\hline
\end{tabular}

The fluctuation of analog output voltage, due to sensor internal noise, when detecting a stationary target is called repeatability.

\subsection{Principle of distance estimation}

Fig. 3 illustrates the sensor principle to estimate the distance to target where:

$\mathrm{d}_{\mathrm{L}}$ : Distance to laser,

$\mathrm{d}_{\mathrm{D}}$ : Distance to detector,

$\beta$ : Angle of incidence,

$\mathrm{d}_{\mathrm{E}}$ : Speculate distance,

$\mathrm{I}_{\mathrm{D}}$ : Intensity on detector,

$\mathrm{x}_{\mathrm{L}}$ : $\mathrm{x}$-axis component of incident laser beam,

$\mathrm{y}_{\mathrm{L}}: \mathrm{y}$-axis component of incident laser beam,

$\mathrm{x}_{\mathrm{D}}: \mathrm{x}$-axis component of reflected laser beam,

$\mathrm{y}_{\mathrm{D}}: \mathrm{y}$-axis component of reflected laser beam, 


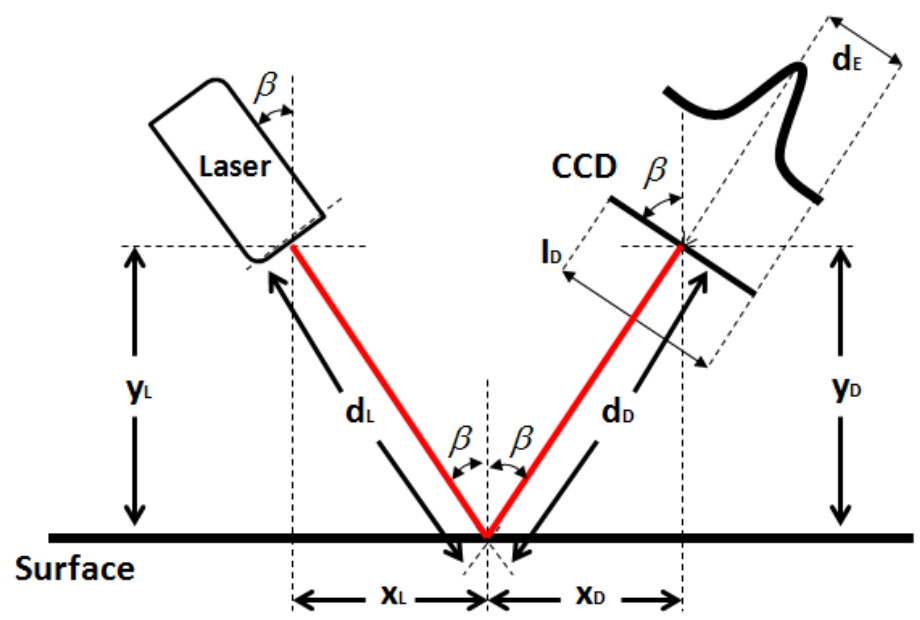

Fig. 3. Measurement principle of distance.

According to the law of reflection, the reflected beam has the same angle that the incident, so we have:

$$
\frac{x_{L}}{y_{L}}=\frac{x_{D}}{y_{D}}
$$

The normal density function (Gaussian curve), in Fig. 3, represents the laser beam intensity detected by the CCD and corresponds to the distance to the speculate $\left(\mathrm{d}_{\mathrm{E}}\right)$ from the laser to the object surface. This distance is defined by:

$$
f(x-\mu)=\frac{1}{\sigma \sqrt{2 \pi}} e^{-\frac{1}{2}\left(\frac{x-\mu}{\sigma}\right)^{2}},
$$

where $\sigma$ is the standard deviation and $\mu$ is the average intensity obtained by the CCD detector.

Fig. 4 shows how a variation $(\Delta y)$ in the distance to the object's surface (displacement) produces a change in the mean of the Gaussian curve.

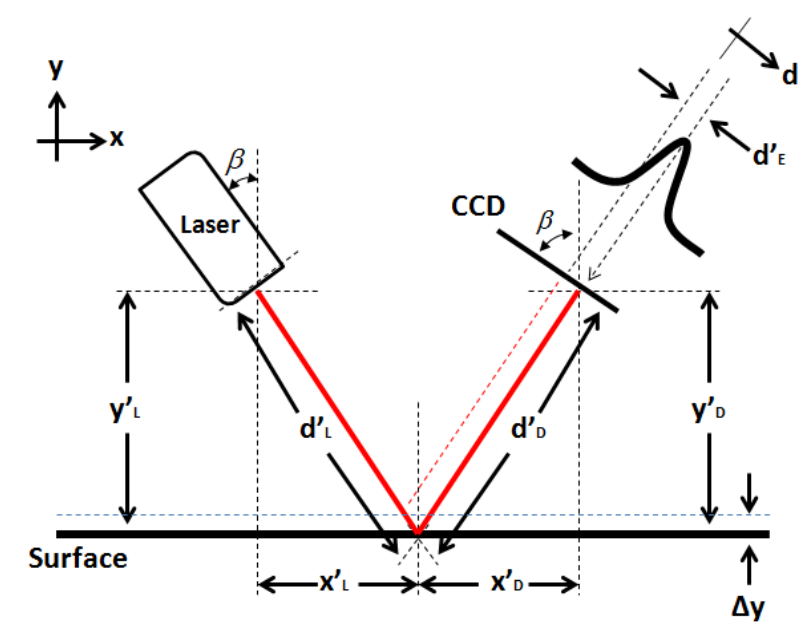

Fig. 4. Measuring displacements of object's surface. 
Fig. 5 shows the relationship between the displacement of the Gaussian curve $d^{\prime}{ }_{E}$ and the displacement $\Delta \mathrm{y}$ is given by:

$$
\Delta y=-d^{\prime}{ }_{E} \cos (\beta)
$$

Since the measuring range of CCD is limited, the maximal variation $\Delta y$ is given by:

$$
\Delta y \operatorname{Max}=\frac{I_{D}}{2} \cos (\beta) .
$$

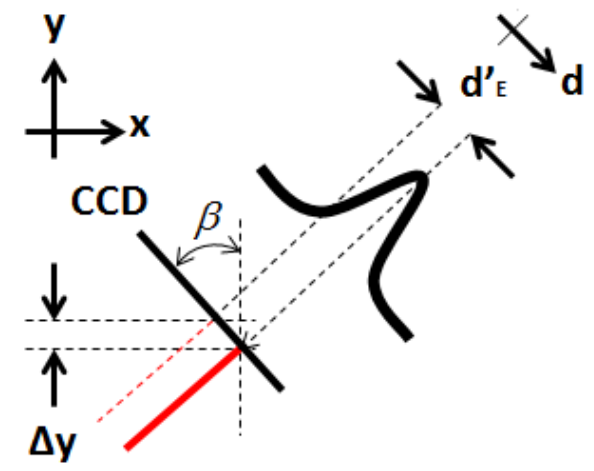

Fig. 5. Relationship between distance to specular and $\Delta y$.

The edges of the profile are not measured as the light intensity is lacking.

\subsection{Estimation of $3 D$ coordinates}

The purpose of distance measurement by laser triangulation is to calculate the radius $(r)$, which is the distance from the center of the object holder to the point where the laser beam strikes the object, see Fig. 6.

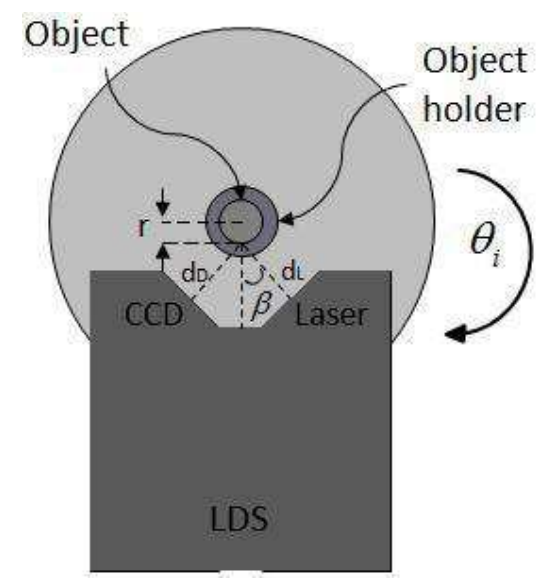

Fig. 6. Laser triangulation measurement.

The object is mounted on the object holder. Fig. 6 shows a circle shaped object, the laser beam is projected onto the object surface and reflected towards the CCD. The angular positioning system rotates using a constant increment $\left(\Delta \alpha=0.9^{\circ}\right)$ which is calculated by dividing $360^{\circ}$ by the number $\mathrm{N}$ of steps of the motor $(\mathrm{N}=400)$. The $3 \mathrm{D}$ coordinates of each 
point of the object surface, $D_{i}=\left(x d_{i}, y d_{i}, z d_{i}\right)$, are obtained from $r_{i}, i=1,2,3 \ldots N$ and $\beta_{i}$ as follows:

$$
\left[\begin{array}{l}
x d_{i} \\
y d_{i} \\
z d_{i}
\end{array}\right]=\left[\begin{array}{ccc}
\cos \beta_{i} & 0 & 0 \\
0 & \sin \beta_{i} & 0 \\
0 & 0 & 1
\end{array}\right]\left[\begin{array}{c}
r_{i} \\
r_{i} \\
z_{i}
\end{array}\right],
$$

where $\beta_{i}=\beta_{i-1}+\Delta \alpha$. The value of $z_{i}$ is also a constant defined by the increments of the micrometer.

\subsection{Shape parameters}

The spheres and cubes are the only objects whose size can be given for only a number (diameter or length). Food powder particles are irregularly shaped particles and their characterization requires several parameters of size and shape [11]. The shape parameters used in this work are based on the three representative lengths: $L$ (longest dimension), $W$ (intermediate dimension) and $T$ (shortest dimension) [15], see Fig. 7. These lengths are equivalent to the lengths of the sides of a solid rectangle of a particle boundary, as shown in Fig. 7.

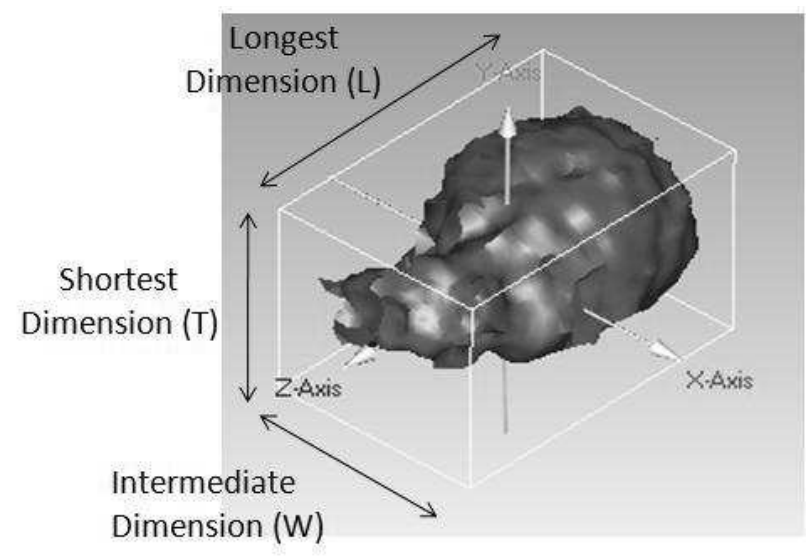

Fig. 7. Main dimensions of an irregular particle.

The elongation ratio $(E R)$ is defined as:

$$
E R=\frac{W}{L}
$$

For circular objects $E R$ is equal to 1 . The more elongated shape, the greater is its elongation factor [11].

The flatness ratio $(F R)$ and the aspect ratio (AR) are defined as:

$$
\begin{gathered}
F R=\frac{T}{W}, \\
A R=\frac{L}{W},
\end{gathered}
$$

respectively. 
The shape factor (SF) has been used to describe the irregularity of the surface and is defined as:

$$
S F=\frac{T}{\sqrt{W L}} .
$$

Fig. 8 shows the numerical values and the corresponding shapes for parameters $A R$ and $S F$.

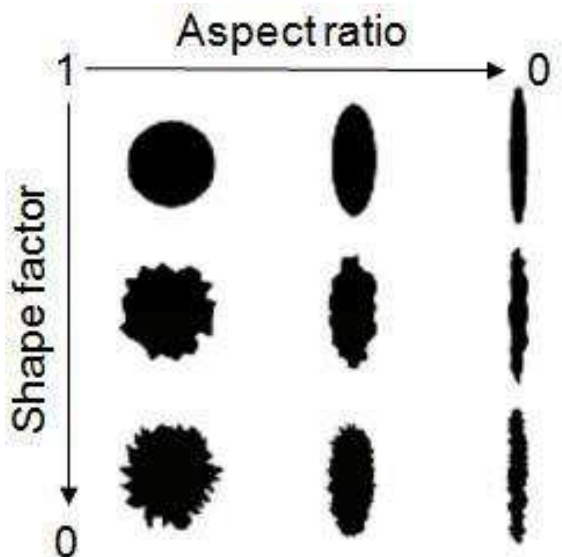

Fig. 8. Aspect ratio and Shape factor parameters relationship.

From 3D coordinates of the object surface, obtained from the LDS, one can estimate the particle sphericity $(S p)$. The sphericity value is set in a range of 0 to 1 , where a value of 1 indicates a perfect sphere [15]. The sphericity is defined as follows:

$$
S p=\frac{d_{n}}{L}
$$

Nominal diameter $d_{n}$ and nominal surface $s_{n}$ are computed as follows:

$$
\begin{gathered}
d_{n}=\left(\frac{6 V}{\pi}\right)^{\frac{1}{3}}, \\
s_{n}=\left(36 \pi V^{2}\right)^{\frac{1}{3}},
\end{gathered}
$$

respectively.

The volume $V$ and lengths $L, W$ and $T$ of the agglomerated particles may be obtained from the $3 \mathrm{D}$ coordinates estimated by the LDS.

\section{Experimental validation}

To validate the technique presented in this manuscript, we used three simple geometry objects whose dimensions are easily measured manually: a sphere, a cylinder and a hex nut. Objects have dimensions within the range of 1 to $2 \mathrm{~mm}$. Using the 3D coordinates derived from Eq. (5), a cloud of points can be obtained as well as a textured representation of the object, see Fig. 9. 

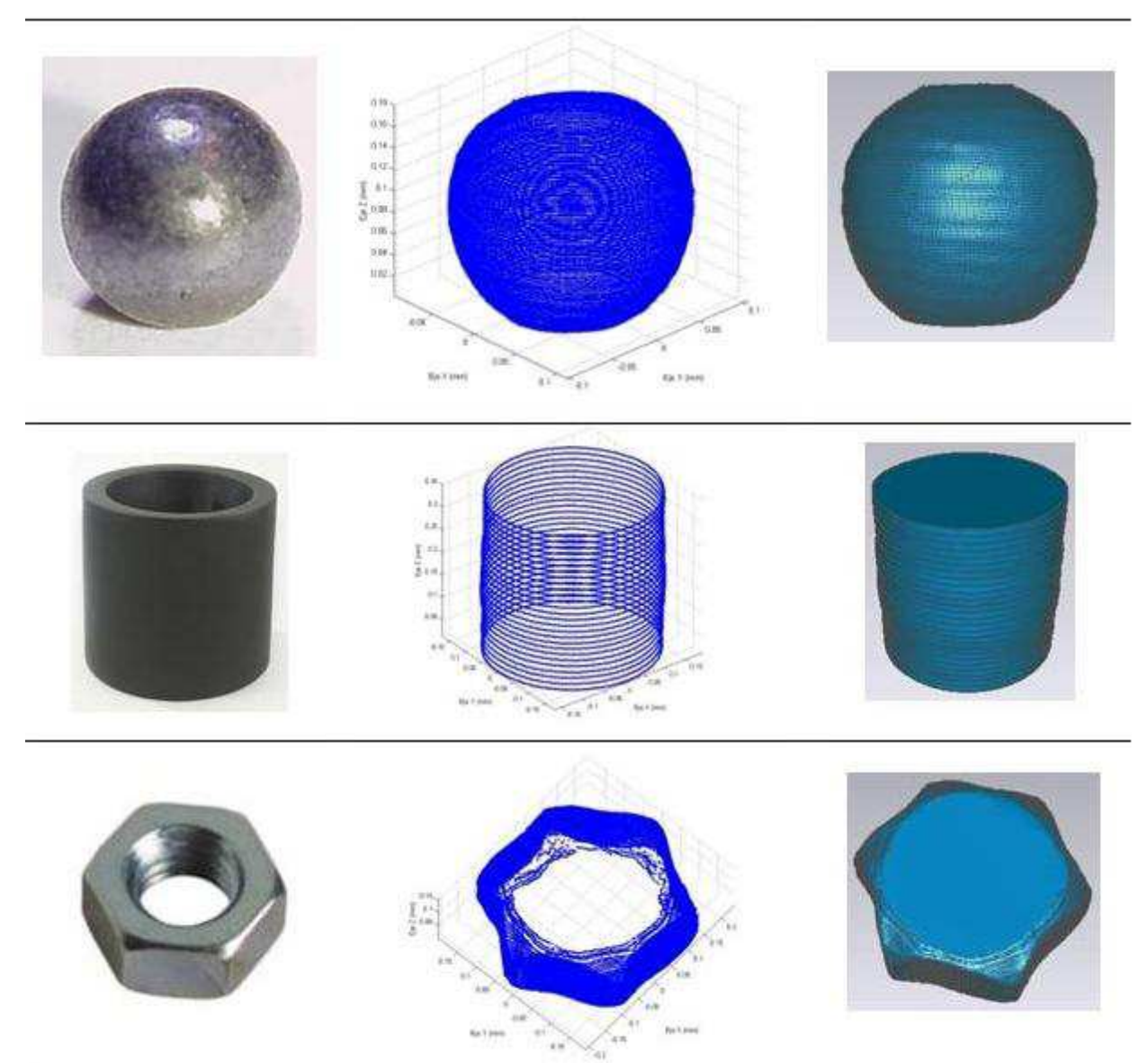

a)

b)

c)

Fig. 9. Objects to validate the technique, a) real objects, b) cloud of 3D points, c) textured object.

Table 2 presents the results obtained by measuring the dimensions of the objects shown in Fig. 9 with a caliper and from the 3D model obtained by the LDS. Consider that, in principle, resolution and accuracy obtained with the LDS are better than those obtainable with the caliper.

Table 2. Numerical values of shape parameters.

\begin{tabular}{|c|c|c|c|c|c|c|c|c|c|}
\hline Object & $\begin{array}{l}\text { Volume } \\
\left(\mathrm{mm}^{3}\right)\end{array}$ & $\begin{array}{l}\text { LDS } \\
\text { Volume } \\
\left(\mathrm{mm}^{3}\right)\end{array}$ & $\begin{array}{l}\text { Error } \\
\text { V (\%) }\end{array}$ & $\begin{array}{l}\text { Surface } \\
\underset{\left(\mathrm{mm}^{2}\right)}{\operatorname{area}} \mathbf{S}_{\mathbf{n}}\end{array}$ & $\begin{array}{l}\text { LDS } \\
\text { Surface } \\
\underset{\left(\mathbf{m m}^{2}\right)}{\operatorname{area} \mathbf{S}_{\mathbf{n}}}\end{array}$ & $\begin{array}{l}\text { Error } \\
S_{n}(\%)\end{array}$ & $\begin{array}{l}\text { Sphericity } \\
\text { Sp }\end{array}$ & $\begin{array}{l}\text { LDS } \\
\text { Sphericity } \\
\text { Sp }\end{array}$ & $\begin{array}{l}\text { Error Sp } \\
(\%)\end{array}$ \\
\hline Sphere & 1.577 & 1.552 & 1.585 & 6.551 & 6.482 & 1.053 & 1.0 & 0.988 & 1.2 \\
\hline Cylinder & 1.812 & 1.797 & 0.827 & 7.187 & 7.147 & 0.556 & 0.874 & 0.847 & 3.089 \\
\hline Hex nut & 1.62 & 1.565 & 3.39 & 6.67 & 6.518 & 2.27 & 0.77 & 0.7394 & 3.06 \\
\hline
\end{tabular}

Values of caliper are used as reference to compute the error. In the case of hex nut, its volume was estimated considering a hexagonal prism. 


\section{Parameter extraction from agglomerates}

\subsection{Test agglomerates}

To carry out the experimental part of this work, 10 samples of milk powder agglomerates were obtained using the fluidized bed technique, see Fig. 10. The particles were divided into three size fractions by sieving: up to $630 \mu \mathrm{m}$ for size A, up to $1250 \mu \mathrm{m}$ for size B and from 630 to $1250 \mu \mathrm{m}$ for size C. Prior to analysis, the agglomerates were stored for one week in a desiccator with silica gel for drying.

For weighing of the individual agglomerates, a laboratory precision balance (AX205 Delta Range, Mettler Toledo, France) was used. This balance has a precision of $0.01 \mathrm{mg}$ with a weighing error that might be up to $0.005 \mathrm{mg}$. It was therefore not sufficient for individual agglomerates in the small size fraction (inferior to $630 \mu \mathrm{m}$ ). For this reason, only agglomerates larger than $630 \mu \mathrm{m}$ were considered for the measurement of shape using 3D reconstruction method.

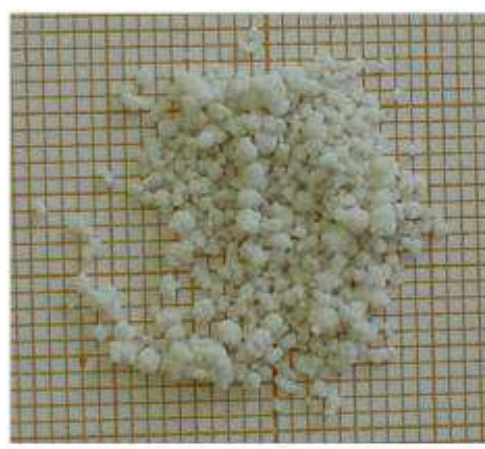

a)

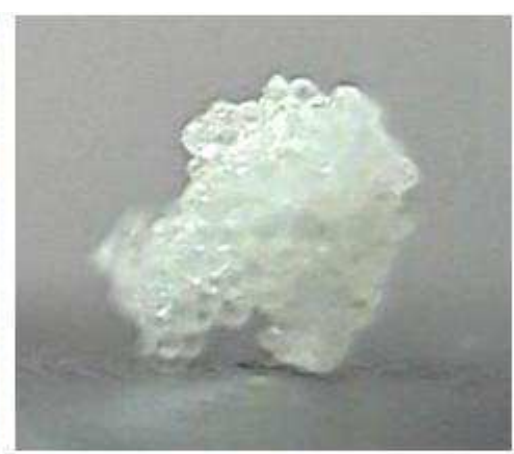

b)

Fig. 10. a) Agglomerates samples, b) zoomed view of one agglomerate.

\subsection{Shape parameters estimation}

The experiment was conducted at an ambient temperature of $24^{\circ} \mathrm{C}$. The agglomerate was mounted on object holder, as shown in Fig. 11. There is not a particular procedure to mount the object. What it should be known in advance is the rotation center of the mechanical system with respect to laser sensor. Ten repeated measurements were performed. The LDS was placed at a distance of $10 \mathrm{~mm}$ to the center of the object holder.

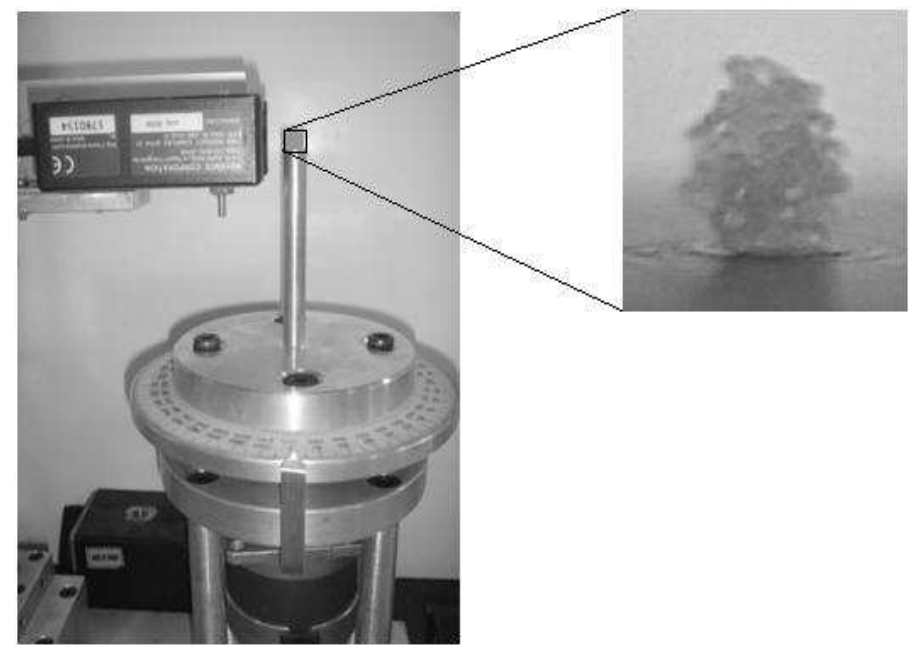

Fig. 11. Agglomerate mounted on the positioning system for scanning. 
Fig. 12 shows real images of two of ten agglomerates used in this experiment, the obtained cloud of $3 \mathrm{D}$ points, and a textured representation of the agglomerate.
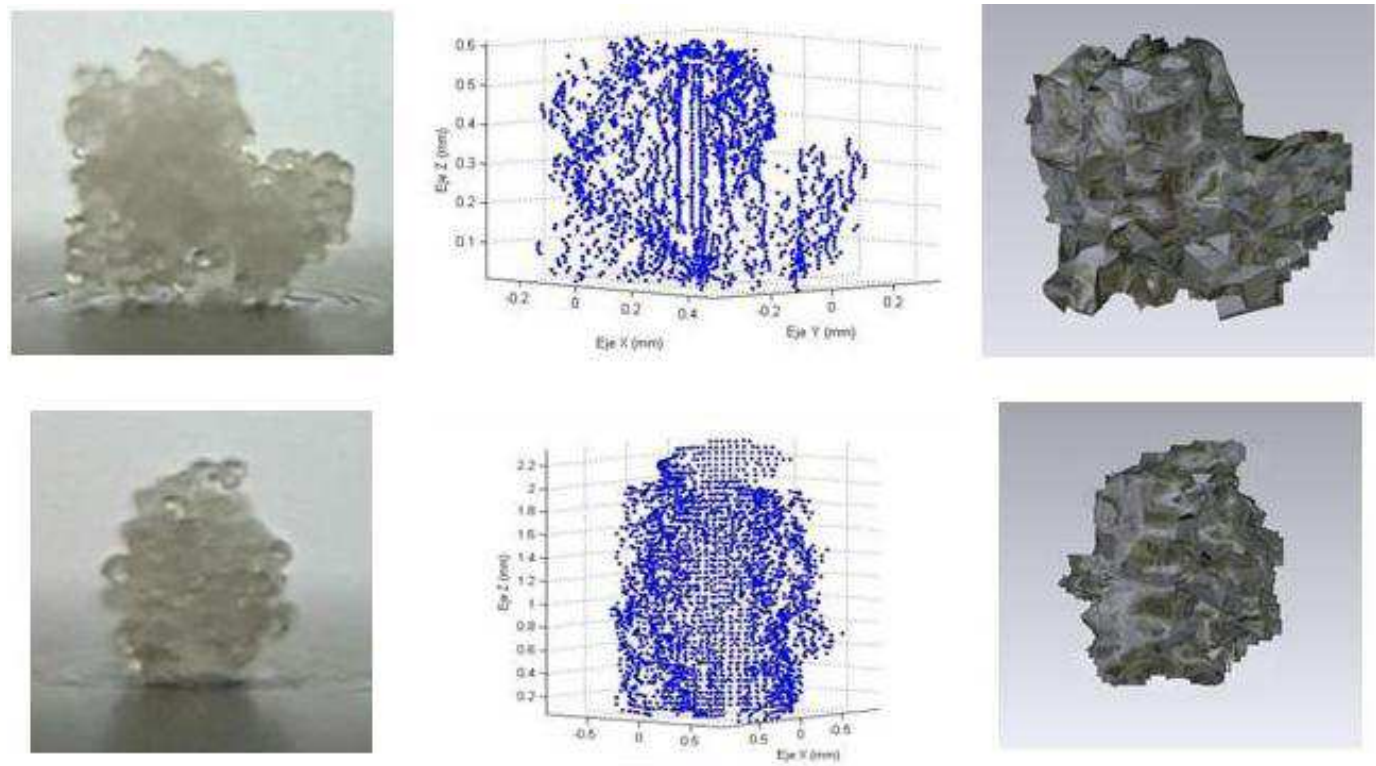

a)

b)

c)

Fig. 12. a) Real agglomerate, b) cloud of 3D points, c) textured object.

Table 3. Shape parameters computed for ten agglomerates.

\begin{tabular}{|c|c|c|c|c|c|c|c|c|c|c|}
\hline No. & $\begin{array}{c}\text { Volume } \\
\left(\mathrm{mm}^{3}\right) \\
\mathrm{V}\end{array}$ & $\begin{array}{l}\text { Surface } \\
\text { area } \\
\left(\mathrm{mm}^{2}\right) \mathrm{s}_{\mathrm{n}}\end{array}$ & $\begin{array}{c}\mathbf{L} \\
(\mathbf{m ~ m}) \\
(\mathbf{m ~ m})\end{array}$ & $\underset{(\mathrm{m} \mathrm{m}}{\mathrm{W}}$ & $\mathbf{T}$ & $\begin{array}{c}\text { Elongation } \\
\text { ratio ER }\end{array}$ & $\begin{array}{c}\text { Flatness } \\
\text { ratio } \\
\text { FR }\end{array}$ & $\begin{array}{c}\text { Aspect } \\
\text { ratio } \\
\text { AR }\end{array}$ & $\begin{array}{c}\text { Shape } \\
\text { Factor } \\
\text { SF }\end{array}$ & $\begin{array}{c}\text { Sphericity } \\
\text { Sp }\end{array}$ \\
\hline 1 & 0.18 & 1.06 & 0.85 & 0.64 & 0.56 & 0.75 & 0.87 & 1.34 & 0.75 & 0.68 \\
\hline 2 & 2.17 & 8.11 & 2.51 & 1.64 & 1.53 & 0.65 & 0.93 & 1.53 & 0.75 & 0.64 \\
\hline 3 & 1.93 & 7.51 & 2.35 & 1.73 & 1.63 & 0.74 & 0.94 & 1.36 & 0.81 & 0.66 \\
\hline 4 & 1.34 & 5.89 & 2.16 & 1.61 & 1.43 & 0.74 & 0.89 & 1.34 & 0.77 & 0.63 \\
\hline 5 & 0.19 & 1.59 & 0.84 & 0.68 & 0.58 & 0.81 & 0.85 & 1.23 & 0.77 & 0.84 \\
\hline 6 & 1.22 & 5.52 & 1.81 & 1.32 & 1.25 & 0.73 & 0.95 & 1.37 & 0.81 & 0.73 \\
\hline 7 & 1.68 & 6.82 & 2.35 & 1.89 & 1.33 & 0.80 & 0.70 & 1.24 & 0.63 & 0.63 \\
\hline 8 & 0.99 & 4.79 & 1.87 & 1.38 & 1.11 & 0.74 & 0.81 & 1.36 & 0.69 & 0.66 \\
\hline 9 & 2.06 & 7.82 & 2.41 & 1.99 & 1.47 & 0.82 & 0.74 & 1.21 & 0.67 & 0.65 \\
\hline 10 & 1.58 & 6.55 & 2.38 & 1.81 & 1.34 & 0.76 & 0.57 & 1.31 & 0.65 & 0.61 \\
\hline
\end{tabular}

Agglomerated particles were scanned using the three dimensional reconstruction technique based on LDS as shown in Fig. 11. Based on the representative three lengths: $L, W$ and $T$, were determined to describe the shape parameters presented in Table 3. It is evident that the agglomerates are near to spherical. The agglomerates are the extreme case, in which variations of volume, surface area, $E R, F R, A R$ and $S F$ depends on the form of agglomerates due to irregular shape. 


\section{Conclusions}

This paper presents an experimental validation of a 3D reconstruction technique of milk powder agglomerates based on a laser displacement sensor. This technique allows the estimation of the particles volume $(V)$ and surface $\left(s_{n}\right)$ as well as some size lengths $(L, W, T)$ to determine some shape parameters $(E R, F R, A R, S F, S p)$. Since we have a $3 \mathrm{D}$ cloud of points, a textured representation of the agglomerate is also available.

As expected, the reconstructed object has errors associated with the discretization of the data. Those errors are less than $1 \%$ considering only scanning along z-axis. We are considering that $\mathrm{z}$-axis error is the highest in our experimental set-up. The smaller the $\mathrm{z}$-axis increment, the better the accuracy. Accuracy was estimated considering a sphere as reference, assuming that agglomerates have spherical shape.

The experimental results demonstrate the feasibility of this technique to estimate the shape parameters of agglomerate small particles that can be generalized for other kind of objects. A better accuracy is possible simply by increasing the number of points per turn (on the angular positioning system), for example by using a DC servomotor instead of a step motor. In the same way, accuracy can be improved by reducing the increments in the z-axis using a DC servomotor to move the LSD.

Since angular and linear increments are small and slow, the sample remains stable. For instance, scanning time is around 2 hours, but we can improve it by increasing angular and linear velocities.

Perspectives for our work mainly are that the method presented could be use in combination with more complex morphological analyses [16] o to validate other optical particle characterization methods [17].

\section{Acknowledgements}

The authors acknowledge the government agency CONACyT for the financial support scholarship number 206481. Authors acknowledge to Enrique Miranda Muñoz for his help to implement the positioning system.

\section{References}

[1] Schubert H. (1987). Food particle technology: Part I. Properties of particles and particulate food systems. Journal Food Engineering, 6(1), 1-32.

[2] Mekki B.K., Pons M.N., Falk V., Vivier H. (2002). Recherche de relations entre la coulabilité et la morphologie des poudres, Groupe "solides divisés" de la SFGP.

[3] Tanguy P.A., Thibault F., Dubois C., Aït-Kadi A. (1999). Mixing hydrodynamics in a double planetary mixer. Chemical Engineering Research and Design, 77(4), 318-324.

[4] Valdek M., Helmo K., Priit K., Michal B. (2001). Characterization of Powder Particle Morphology. Proc. Estonian Acad. Sci. Eng., 7(1), 22-34.

[5] Turchiuli C., Eloualia Z., El-Mansouri N., Dumoulin E. (2005). Fluidised bed agglomeration: Agglomerates shape and end-user properties. Powder Technology, 157(1-3), 168-175.

[6] Pawley J.B. (2006). Handbook of Biological Confocal Microscopy, 3rd ed. Springer, Berlin.

[7] Emeruwa E., Jarrige J., Mexmain J., Bernardin M. (1991). Application of mercury porosimetry to powder $\left(\mathrm{UO}_{2}\right)$ analysis. Journal of Nuclear Materials, 184(1), 53-58.

[8] Hogekamp S., Pohl M. (2003). Porosity measurement of fragile agglomerates. Powder Technology. 130, 385-392. 
[9] Turchiuli C., Castillo C.E. (2009). Agglomerates structure characterization using 3D-image reconstruction. Particle and Particle Systems Characterization, 26, 25-33.

[10] Castillo C.E., Turchiuli C. (2008). Volume estimation of small particles using three-dimensional reconstruction from multiple views. ICISP '08 Proc. of the 3rd International Conference on Image and Signal Processing, 218-225.

[11] Saad M., Sadoudi A., Rondet E., Cuq B. (2011). Morphological characterization of wheat powders, How to characterize the shape of particles?. Journal Food Engineering, 102, 293-301.

[12] Alander E.M., Uusi-Penttilä M.S., Rasmuson A.C. (2003). Characterization of paracetamol agglomerates by image analysis and strength measurement. Powder Technology, 130, 298-306.

[13] Realpe A., Velázquez C. (2006). Pattern recognition for characterization of pharmaceutical powders. Powder Technology, 169, 108-113.

[14] http://www.keyence.com/products/measure/laser/laser.php (December 2011).

[15] Yuichi H., Takashi O. (2005). Evaluation of gravel sphericity and roundness based on surface-area measurement with a laser scanner. Computers and Geosciences, 31, 735-741.

[16] Wozniak M., Onofri F.R.A., Barbosa S., Yon J., Mroczka J. (2012), Comparison of methods to derive morphological parameters of multi-fractal samples of particle aggregates from TEM images. Journal of Aerosol Science, 47, 12-26.

[17] Mroczka J., Woźniak M., Onofri F.R.A. (2012), Algorithms and methods for analysis of the optical structure factor of fractal aggregates. Metrology and Measurement Systems, XIX (3), 459-470. 